\title{
Spraying N-butyl-2-cyanoacrylate (Histoacryl) as a rescue therapy for gastrointestinal malignant tumor bleeding after failed conventional therapy
}

We report here on five cases of bleeding gastrointestinal malignant tumors treated by spraying N-butyl-2-cyanoacrylate (Histoacryl) on the lesion with satisfactory results $(\bullet$ Table $\mathbf{1})$. The first case was a 84-year-old man who presented with recurrent upper gastrointestinal bleeding since a few days. Esophagogastroduodenoscopy (EGD) revealed a 5-cm gastric cancer at the lesser curvature with oozing. Epinephrine $(1: 20000)$ was injected into the tumor to slow down the bleeding, following which Histoacryl (cyanoacrylate $0.5 \mathrm{~mL}$ with Lipiodol $0.8 \mathrm{~mL}$ per aliquot) was sprayed via a $23-G$ needle catheter (InterjectTM, Boston Scientific, Massachusetts, USA) ( $\bullet$ Fig. 1 ) over the tumor surface, followed by sterile water until hemostasis was achieved. The patient had no overt bleeding at 9 weeks after the procedure. The second case was a 76-year-old woman with cryptogenic cirrhosis who presented with recurrent lower gastrointestinal bleeding. Colonoscopy revealed a $5-\mathrm{cm}$ sessile polyp in the ascending colon with oozing. Epinephrine was injected and Histoacryl sprayed using the same technique as described above, and the bleeding stopped. The third case was a 15 -year-old boy with a metastasizing germinoma with tumor invasion of the second portion of the duodenum. The bleeding was stopped using the same technique again. The patient had recurrent bleeding $48 \mathrm{~h}$ later, which was successfully stopped by angio-embolization. The fourth case involved a 56-year-old man with pancreatic

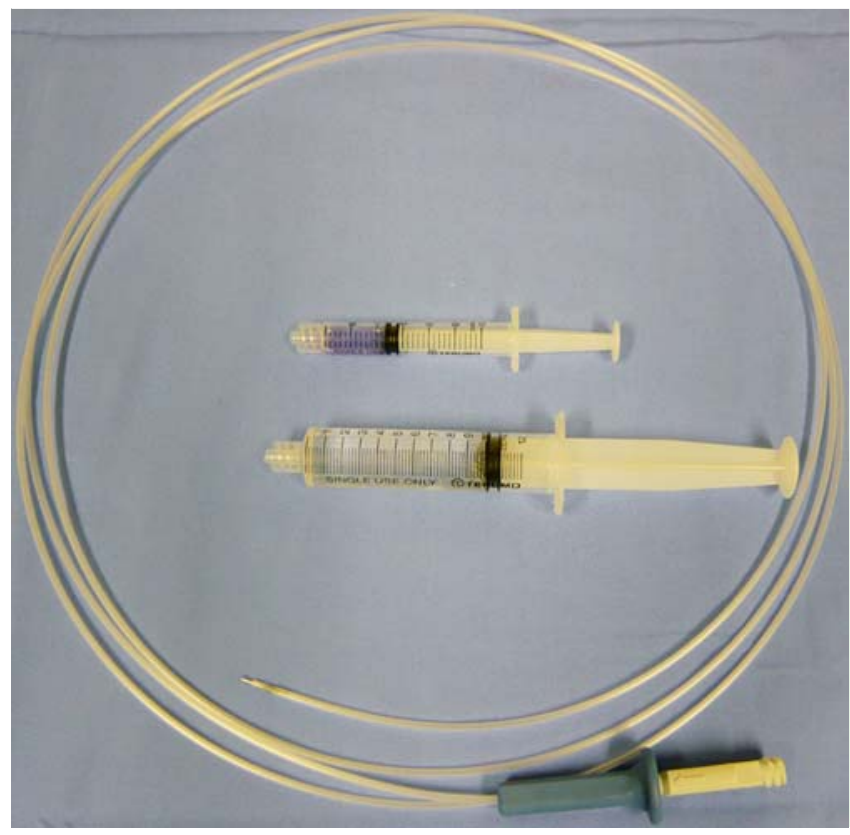

Fig. 1 The instruments used for spraying Histoacryl.

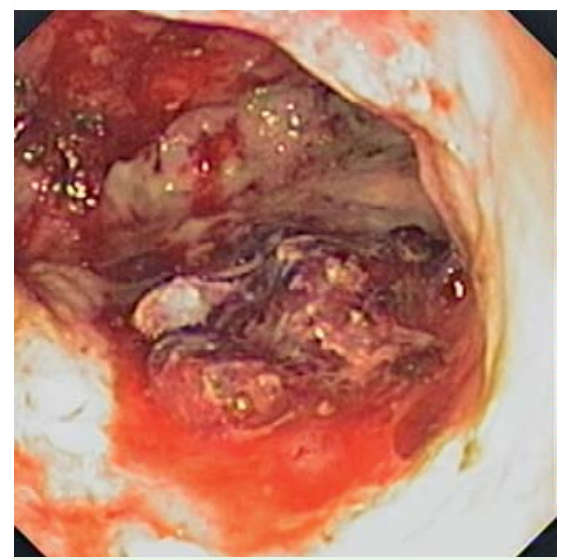

Fig. 2 Active oozing from the gastric tumor surface.

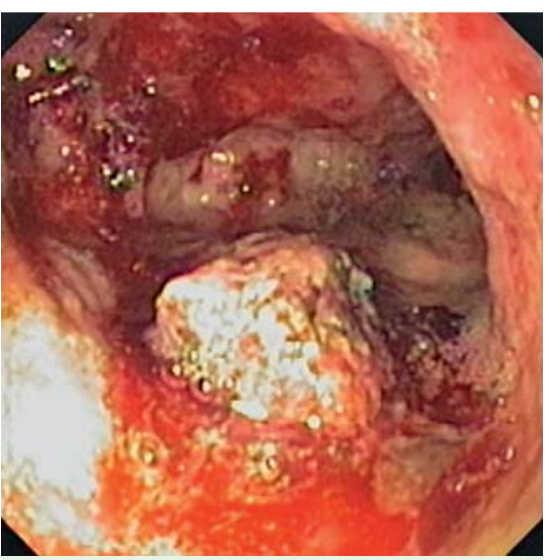

Fig. 3 View after initial Histoacryl spray.

Table 1 Clinical outcomes of the patients.

\begin{tabular}{|c|c|c|c|c|c|c|c|}
\hline $\begin{array}{l}\mathrm{Pa}- \\
\text { tient } \\
\text { no }\end{array}$ & $\begin{array}{l}\text { Age } \\
\text { and } \\
\text { sex }\end{array}$ & $\begin{array}{l}\text { Type of } \\
\text { malignancy }\end{array}$ & Epinephrine injection & $\begin{array}{l}\text { Histoacryl } \\
\text { spray (mL) }\end{array}$ & $\begin{array}{l}\text { Initial } \\
\text { homeostasis }\end{array}$ & $\begin{array}{l}\text { Re-bleeding } \\
\text { (72 h) }\end{array}$ & Intermediate outcome \\
\hline 1 & $84 \mathrm{M}$ & Gastric cancer & Yes & 3.0 & Yes & No & $\begin{array}{l}\text { Still alive, no re-bleeding } \\
\text { at } 9 \text { weeks }\end{array}$ \\
\hline 2 & $76 \mathrm{~F}$ & Malignant colonic polyp & Yes & 2.0 & Yes & No & $\begin{array}{l}\text { Dead, no re-bleeding } \\
\text { at } 5 \text { weeks }\end{array}$ \\
\hline 3 & $15 \mathrm{M}$ & Duodenal cancer & Yes & 1.0 & Yes & Yes & $\begin{array}{l}\text { Continue to bleed and } \\
\text { still alive }\end{array}$ \\
\hline 4 & $56 \mathrm{M}$ & $\begin{array}{l}\text { Pancreatic cancer with } \\
\text { gastric wall invasion }\end{array}$ & No, with metallic clip & 1.0 & Yes & No & $\begin{array}{l}\text { Still alive, No re-bleeding } \\
\text { at } 6 \text { weeks }\end{array}$ \\
\hline 5 & $62 \mathrm{~F}$ & Ampullary carcinoma & $\begin{array}{l}\text { Yes with argon plasma } \\
\text { coagulation (failed em- } \\
\text { bolization at first step) }\end{array}$ & 1.5 & Yes & No & $\begin{array}{l}\text { Dead, no re-bleeding } \\
\text { at } 9 \text { weeks }\end{array}$ \\
\hline
\end{tabular}




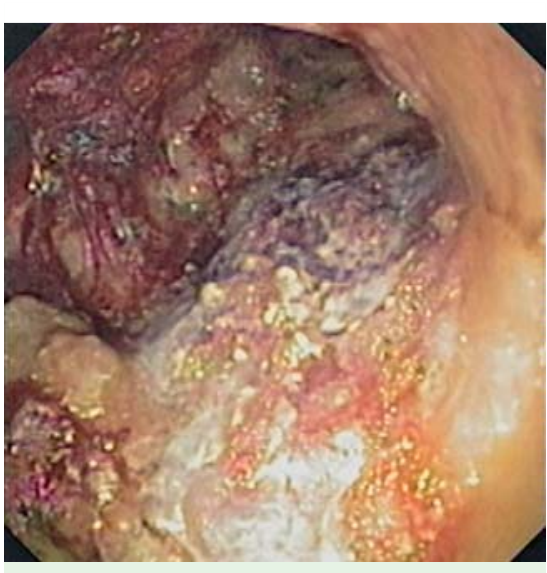

Fig. 4 Bleeding stopped successfully.

mass and gastric wall invasion. EGD showed a 6-cm ulcerating mass with oozing in the upper part of the lesser curvature ( $\bullet$ Fig. 2, 3). A metal clip was applied at the bleeding site but failed to stop it. Therefore, Histoacryl was sprayed and the bleeding stopped ( $\bullet$ Fig. 4). Lastly, a 62 -year-old woman, a known case of advanced ampullary carcinoma invading the second portion of the duodenum, was referred for EGD after failed epinephrine injection, argon plasma coagulation (APC), and angio-embolization. Histoacryl spray was again used to stop the bleeding. In our experience, the use of Histoacryl spray for initial hemostasis of bleeding tumors led to impressive results, with a low risk of immediate and delayed recurrent bleeding after the procedure. The procedure itself was easy to carry out and without complications. No special techniques or equipment were required. Therefore, in our opinion, this technique might be suitable as a bridging therapy for bleeding tumors after other failed interventions, but not as the primary method of treatment.

\section{Endoscopy_UCTN_Code_TTT_1AO_2AD \\ Endoscopy_UCTN_Code_TTT_1AQ_2AZ}

Competing interests: None

\section{Prachayakul, P. Aswakul, U. Kachinthorn}

Siriraj Endoscopy Center, Department of Internal Medicine, Bangkok, Thailand

\section{References}

1 Anjiki H, Kamisawa T, Sanaka M et al. Endoscopic hemostasis techniques for upper gastrointestinal hemorrhage: A review. World J Gastrointest Endosc 2010; 2: 54-60

2 Garcia-Tsao G, Bosch J. Management of varices and variceal hemorrhage in cirrhosis. $\mathrm{N}$ Engl J Med 2010; 4: 823-831

3 Shida T, Takano S, Miyazaki M et al. Spraying N-butyl-2-cyanoacrylate (Histoacryl) might be a simple and final technique for bleeding gastrointestinal lesions. Endoscopy 2009; 41: E27-E28

\section{Bibliography}

DOI $10.1055 / \mathrm{s}-0030-1256350$

Endoscopy 2011; 43: E227 -E228

(c) Georg Thieme Verlag KG Stuttgart · New York . ISSN 0013-726X

\section{Corresponding author}

\section{P. Aswakul}

Siriraj Endoscopy Center

Siriraj Hospital - Internal Medicine

Siriraj Hospital

Prannok Road

Bangkok 10700

Thailand

Fax: +662-412-1088

asawakul@gmail.com 